Fournal of Medical Genetics (1973). 10, 135.

\title{
Three Further Cases of Triploidy in Man Surviving to Birth
}

\section{S. WALKER,* J. ANDREWS, $†$ N. M. GREGSON, $\ddagger$ and W. GAULT $† \dagger$}

Summary. Three triploid infants, two male $(69, \mathrm{XXY})$ and one female $(69, \mathrm{XXX})$ all of which survived beyond 35 weeks' gestation are described. One was stillborn due to a difficult delivery, the other two survived for a few hours only. Two were of relatively low birth weight, the other was normal. There was no evidence of mosaicism in the tissue examined.

In keeping with previously reported triploid infants they showed a variety of abnormalities. From a total of 13 cases now reported the more frequent associated anomalies are low set ears, coloboma of the iris, syndactyly of the hands, a single palmar crease, abnormal male genitalia in XXY individuals, polycystic kidney, and congenital heart defect. The most common anomaly, however, is hydatidiform degeneration of a large placenta.

Within the past six years reports on eight completely triploid embryos, having survived 28 weeks' gestation, have appeared in the literature (Bernard et al, 1967; Edwards et al, 1967; PapiernikBerkhauer, 1968; Butler et al, 1969; Keutel, Dollman, and Munster, 1970; Schindler and Mikamo, 1970; Paterson et al, 1971; Schmickel et al, 1971). Two of these cases were stillbirths, the others all survived for periods up to 23 hours after birth. Two other cases of complete triploidy have been reported occurring as late abortions at 24 and 25 weeks' gestational age (Beischer, Fortune, and Fitzgerald, 1967; Paterson et al, 1971).

Over a similar period of time we have seen and report here three further cases of triploidy surviving beyond 35 weeks' gestation (case 1 was referred to in Walker, 1969).

\section{Case Reports and Investigations}

Case 1. The mother, aged 33, had had three previous full term, normal deliveries in 1954, 1955, and 1959. In the affected pregnancy in 1966 she was first

Received 31 October 1972

* Cytogenetics Unit, Nuffield Building, University of Liverpool. + Department of Obstetrics and Gynaecology, University of Liverpool. Present address: University Hospitals of Wales, Cardiff. ¥ Cytogenetics Unit, Nuffield Building, University of Liverpool. Present address : Department of Pathology, General Infirmary, Salisbury.

t† Clatterbridge Hospital, Bebington, Cheshire. seen at hospital when admitted at 38 weeks' gestation with ruptured membranes and a breech presentation. She had been cared for during pregnancy by the district midwife and progress was said to have been normal until the breech presentation was diagnosed following spontaneous rupture of the membranes.

At the time of admission the patient's general condition was good. Blood pressure was normal at 120 / $85 \mathrm{~mm} \mathrm{Hg}$, proteinuria was absent although gross leg oedema was present. There was slight clinical anaemia (haemoglobin $11.0 \mathrm{~g} / 100 \mathrm{ml}$ ). Blood group was A, Rh positive. The uterus was enlarged to a size compatible with 38 weeks' gestation. The breech presented and the fetal heart was heard. Labour commenced spontaneously within an hour of admission and heavily meconiumstained liquor drained. After a 14-hour labour, assisted breech delivery was performed. The head was found to be hydrocephalic and perforation and forceps delivery under general anaesthesia was required to effect delivery. The infant, of indeterminate sex, showed no signs of life. The placenta and membranes were macroscopically normal, but histological examination was not carried out.

Necropsy Findings. The infant was not macerated and weighed $2614 \mathrm{~g}$. The head had been hydrocephalic but had been collapsed by puncture of the vertex. The ears were of normal shape. The left eye was absent although the socket had developed. The right eye protruded slightly. The nose was absent and there was bilateral harelip and a complete cleft palate. The limbs were normal apart from bilateral talipes equinovarus. The external genitalia were represented by a single 
central nubble of tissue with no distinguishable urethral orifice. The scrotal folds were rudimentary and no testes were palpable.

Examination of the heart revealed marked enlargement of the left ventricle with a small right ventricle. The pulmonary artery was hypoplastic with a bicuspid valve. The ductus arteriosus was widely patent. There was a high interventricular septal defect. Both lungs were grossly hypoplastic.

Both pleural and peritoneal cavities contained large effusions of clear yellow fluid. There was splenic congestion, the spleen weighing $12 \mathrm{~g}$. The liver weighed $93 \mathrm{~g}$ and also showed congestion and considerable erythropoiesis. Both adrenal glands were tiny, measuring only $5 \times 3 \times 2 \mathrm{~cm}$ with reduced area of fetal cortical cells.

The left kidney was hypoplastic (weight, $2 \mathrm{~g}$ ) and the right showed marked cystic change with no trace of normal kidney tissue (weight, $8 \mathrm{~g}$ ). The urethra ended blindly at a thin membrane below the possible penis. Rudimentary testes were present in the pelvis.

The skull bones were very thin and the cerebral hemispheres almost entirely absent with a single cyst-like space occupying the cranium. At the base of the skull there was a thin plaque of cerebral tissue, overlying the floor of the middle and anterior fossae. The optic nerves and basal ganglia were rudimentary and the pons and cerebellum small. The corpora quadrigemina were fused into a double mass. The cavity of the fourth ventricle was small with the aqueduct leading into its upper end.

Cytogenetic Studies. Chromosome preparations were obtained from specimens of thymus and spleen after two day's culture. More than 100 cells were counted with the mode being clearly triploid (Table I). No cells of a diploid range were seen. Analysis indicated that the chromosome complement was $2 n=69, X X Y$. Skin was set up in culture but growth was slow and unsatisfactory for chromosome investigation. A comparison of the nuclear areas of these skin culture cells was made with those of control diploid skin cultures. The cells derived from this stillborn infant showed a significant increase in nuclear size which would suggest that they were also triploid (Edwards et al, 1967).
Case 2. The affected pregnancy was the fourth to the 24-year-old woman and her 24-year-old husband. In 1966, her first pregnancy ended in a missed abortion at 27 weeks, fetal movements were never felt and a tiny macerated fetus ( $3 \mathrm{~cm}$ in length) was delivered after induction of abortion by oxytocin infusion. The second, in 1967, at first proceeded apparently normally. Fetal movements were felt from 18 to 23 weeks but then spontaneous abortion occurred. The gestation sac was delivered intact. The fetus measured $10 \mathrm{~cm}$, was macerated but showed no external abnormality. The placenta was $9 \mathrm{~cm}$ in diamenter and showed focal calcification. On neither occasion were maternal hormonal studies or fetal chromosome analysis performed. The third pregnancy in 1969 ended in delivery of a normal female child weighing $3628 \mathrm{~g}$.

At the time the fourth pregnancy was conceived the husband was receiving propranalol and chlorpromazine hydrochloride $50 \mathrm{mg}$ three times daily as treatment for anxiety neurosis. The only history of maternal medication was decyclomine hydrochloride and paracetamol given for nausea and backache in early pregnancy. At 28 weeks' gestation, polyhydramnios was diagnosed which became progressively more troublesome and necessitated hospital admission when the patient was 36 weeks pregnant. At that time the mother's general condition was good with no evidence of anaemia or toxaemia although the abdomen was enlarged by the uterus to the level of the xiphysternum. Girth was measured as 107 $\mathrm{cm}$. A fluid thrill was present. Fetal parts were difficult to define although the fetal heart was heard. There was leg and abdominal wall oedema with leg varices and distended veins over the abdominal wall.

An abdominal $x$-ray revealed no apparent skeletal abnormality of the fetus. 24-hour urine collection yielded $12.5 \mathrm{mg}$ oestriol. Blood group was $\mathrm{O}, \mathrm{Rh}$ positive. Over the following three days the patient's backache worsened and she developed retention of urine. Labour supervened and forceps delivery was performed, the indications being maternal distress and fetal prematurity. The placenta was retained and manually removed. Associated blood loss was $600 \mathrm{ml}$.

The infant, a female was in poor condition and despite attempted resuscitation became and remained cyanosed, dying 8 hours later. Subsequently, the mother had a

TABLE I

CHROMOSOME COUNTS AND ANALYSIS

\begin{tabular}{|c|c|c|c|c|c|c|c|}
\hline \multirow{2}{*}{ Case } & \multirow{2}{*}{ Tissue } & \multicolumn{4}{|c|}{ Cells containing counts of } & \multirow{2}{*}{$\begin{array}{l}\text { Total No. } \\
\text { of Cells }\end{array}$} & \multirow{2}{*}{ Analysis } \\
\hline & & $<68$ & 68 & 69 & 70 & & \\
\hline \multirow{2}{*}{1} & Thymus & 6 & 3 & 41 & - & 50 & $69, \mathrm{XXY}$ \\
\hline & Spleen & 7 & 7 & 37 & - & 51 & \\
\hline 2 & Skin & 4 & 3 & 43 & - & 50 & $69, \mathrm{XXX}$ \\
\hline 3 & Blood & 2 & 2 & 46 & - & 50 & $69, \mathrm{XXY}$ \\
\hline
\end{tabular}


large secondary postpartum haemorrhage necessitating curettage and blood transfusion at another hospital.

Necropsy Findings. The large friable placenta weighed $1583 \mathrm{~g}$ and measured $36 \times 30 \times 5 \mathrm{~cm}$. Microscopic examination revealed it to be immature with some hydropic villi.

The infant weighed $3479 \mathrm{~g}$. The right hand had a long crooked index finger while the left showed syndactyly of ring and middle fingers. There was bilateral talipes equinovarus. The chin was receding although the head was otherwise apparently normal.

Examination of the heart revealed dilatation of the right atrium and hypertrophy of both ventricles, with associated atrial defect. The valves were normal. Cardiac failure was thought to be the cause of death.

There were bilateral pleural effusions with congested lungs. There was gross hepatomegaly and splenic congestion. The thyroid, thymus, adrenal glands, both kidneys, and urinary tract appeared normal apart from some dilatation of the ureters. There were apparently normal ovaries, tubes, uterus, vagina, and female external genitalia.

There was cerebral oedema but no other obvious abnormality of the central nervous system.

Cytogenetic Studies. Blood specimens were not available for study in this case but skin tissue was obtained at necropsy some 72 hours after death. Triploidy was con- firmed from the cells counted (Table I) and chromosome analysis indicated a complement of $2 n=69, X X X$. There was no evidence of mosaicism in this tissue.

Nuclear sex was investigated in the cultured fibroblasts after Feulgen staining. From 256 cells scored $27 \cdot 7 \%$ contained one sex chromatin body and $4.7 \%$ two chromatin bodies.

Case 3. The mother, aged 32, had had two previous full-term normal deliveries in 1966 and 1968. The early part of the affected pregnancy was complicated by the removal of a fibroadenoma of the breast under local anaesthesia when the patient was 8 weeks pregnant. Apart from sporadic vomiting she remained well until 34 weeks' gestation when she had an influenza-like illness. Lack of appetite persisted and when seen by her general practitioner she was found for the first time to be hypertensive. Emergency admission to hospital was arranged. At the time of admission she was complaining of frontal headache, right-sided loin pain, and anorexia. Blood pressure was $160 / 110 \mathrm{~mm} \mathrm{Hg}$, her urine contained 2 $\mathrm{g} /$ litre of protein, and she had considerable leg oedema. The optic fundi were normal. The uterus was enlarged with clinical polyhydramnios present, girth was $92 \mathrm{~cm}$, the lie was longitudinal, with a cephalic presentation, and the fetal heart was heard.

Investigations were as follows: blood group $\mathrm{B}, \mathrm{Rh}$ positive; haemoglobin $12 \cdot 1 \mathrm{~g} / 100 \mathrm{ml}$; urinary vanilyl

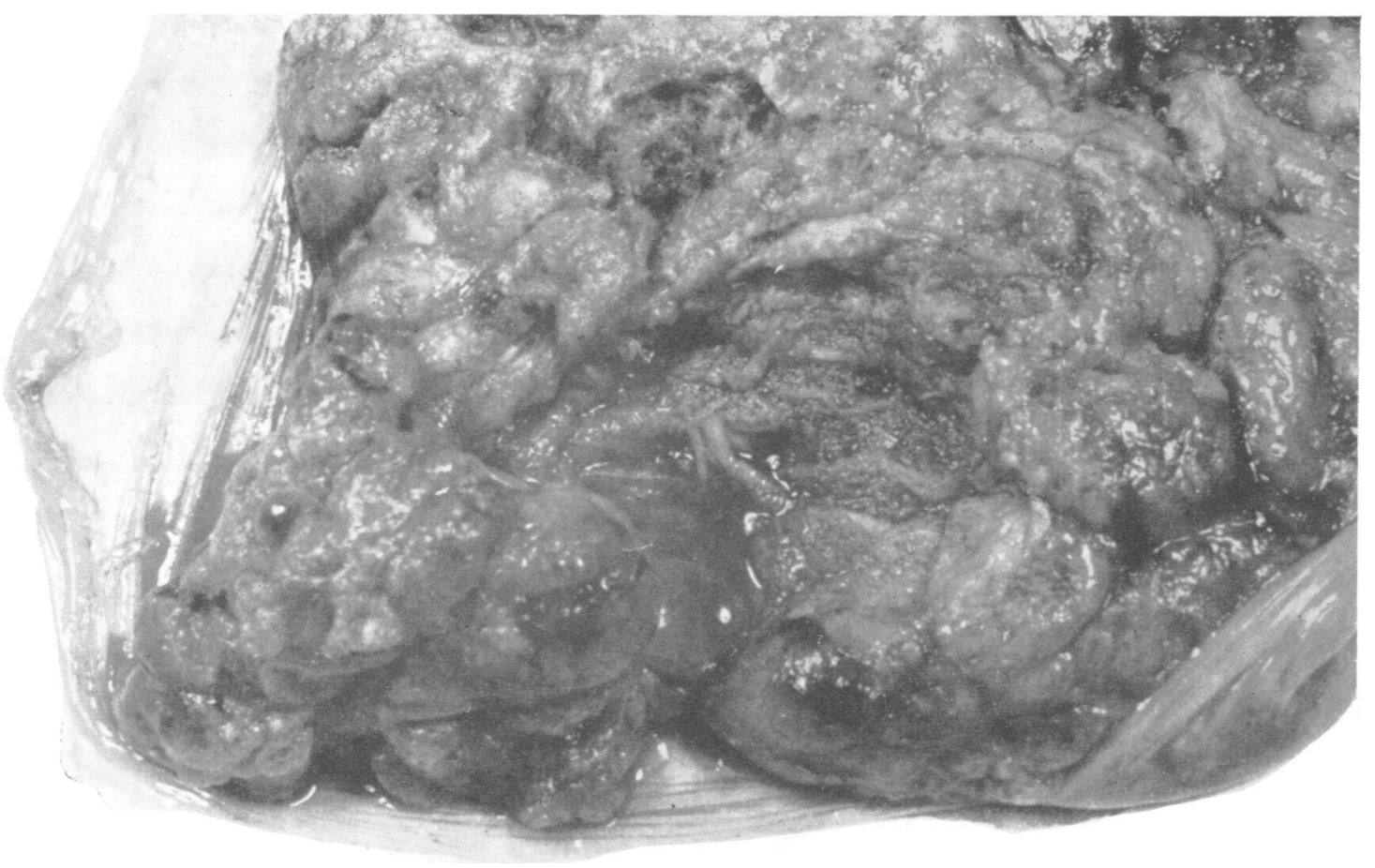

Fig. 1. Portion of the placenta from case 3 showing hydatidiform change. 
mandelic acid $<4 \mathrm{mg} / 24$ hours; urine microscopy revealed pus and coliform bacilli; abdominal $x$-ray revealed no obvious fetal abnormality. The urinary infection was treated with ampicillin.

During the following week the patient complained intermittently of severe headache. Maternal oestriol was measured twice with levels of 3.5 and $3.4 \mathrm{mg} / 24-$ hour urine specimen and in view of these reports and the persistent and worsening hypertension $(180 / 120 \mathrm{~mm} \mathrm{Hg}$ ) labour was induced at 36 weeks' gestation. The hindwaters were ruptured and $400 \mathrm{ml}$ liquor drained. Following oxytocin infusion the patient was delivered normally some 3 hours later. The infant, a male, presented by the head; birth weight was $1845 \mathrm{~g}$. His condition at birth was poor with generalized cyanosis, gasping respiration and rib recession. Despite attempts at resuscitation his condition deteriorated and he died 7 hours later.

The placenta was delivered with difficulty, it weighed $803 \mathrm{~g}$ and measured $18 \mathrm{~cm}$ in diameter. There was macroscopic evidence of hydatidiform change in one part of the placenta (Fig. 1). Microscopy showed many normal villi but also a number which were very large and hydropic with evidence of trophoblastic activity (Fig. 2).

A quantitative assay of urinary chorionic gonadotrophin (pregnosticon) revealed 200,000 IU/litre on the first postpartum day and nil on the eighth day. By this time the urine was free of protein and blood pressure was $145 / 85 \mathrm{~mm} \mathrm{Hg}$.

External examination of the infant revealed a large defect of the occipital bone, head circumference $32 \mathrm{~cm}$, and a cleft palate. The ears were normal in position. The pupils of the eyes were asymmetrical with colobomata of the iris and reduced retinal pattern suggesting retinal colobomata. There was syndactyly of the fingers of both hands, absent finger nails, and a single transverse palmar crease on the left hand only.

Examination of the respiratory and cardiovascular systems revealed only signs of hyaline membrane disease confirmed on radiological examination. The external genitalia suggested male sex but the penis showed hypospadias and the testes were not palpable. Permission for necropsy examination was unfortunately not obtainable. Adrenal hypoplasia was probably present in view of the low maternal oestriol levels recorded.

Cytogenetic Studies. Blood specimens were sent to the laboratory just after the birth of this child with a request to check for a possible trisomy abnormality. By the time cultures had been harvested and found on analysis to be triploid (Table I) with a chromosome complement of $2 \mathrm{n}=69$, XXY (Fig. 3) it was too late to obtain any other tissue specimens. No further investigation could therefore be made. An additional 100 cells were scored from

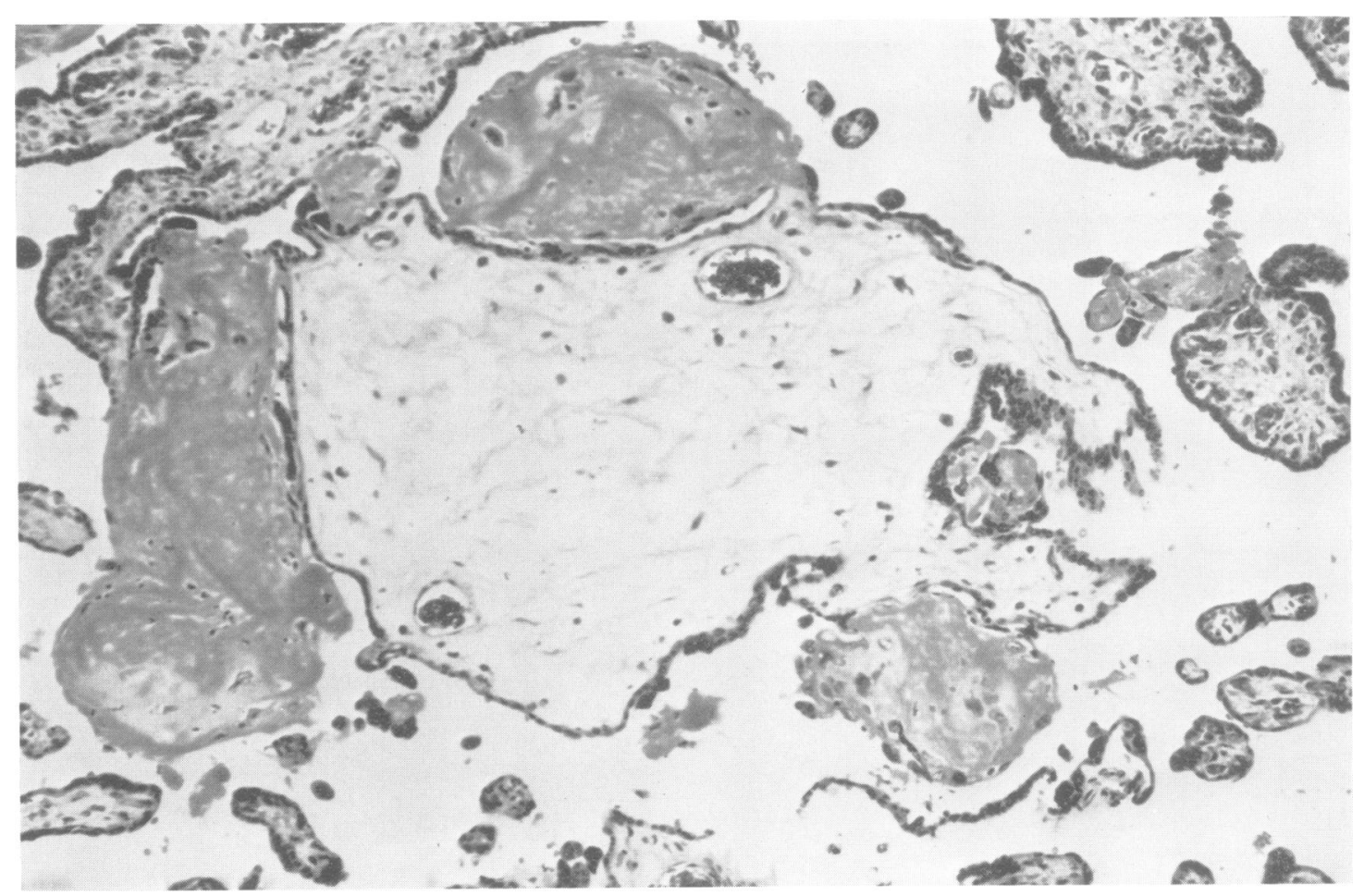

FIG. 2. Section through placental tissue from case 3 showing both normal and hydropic villi. 


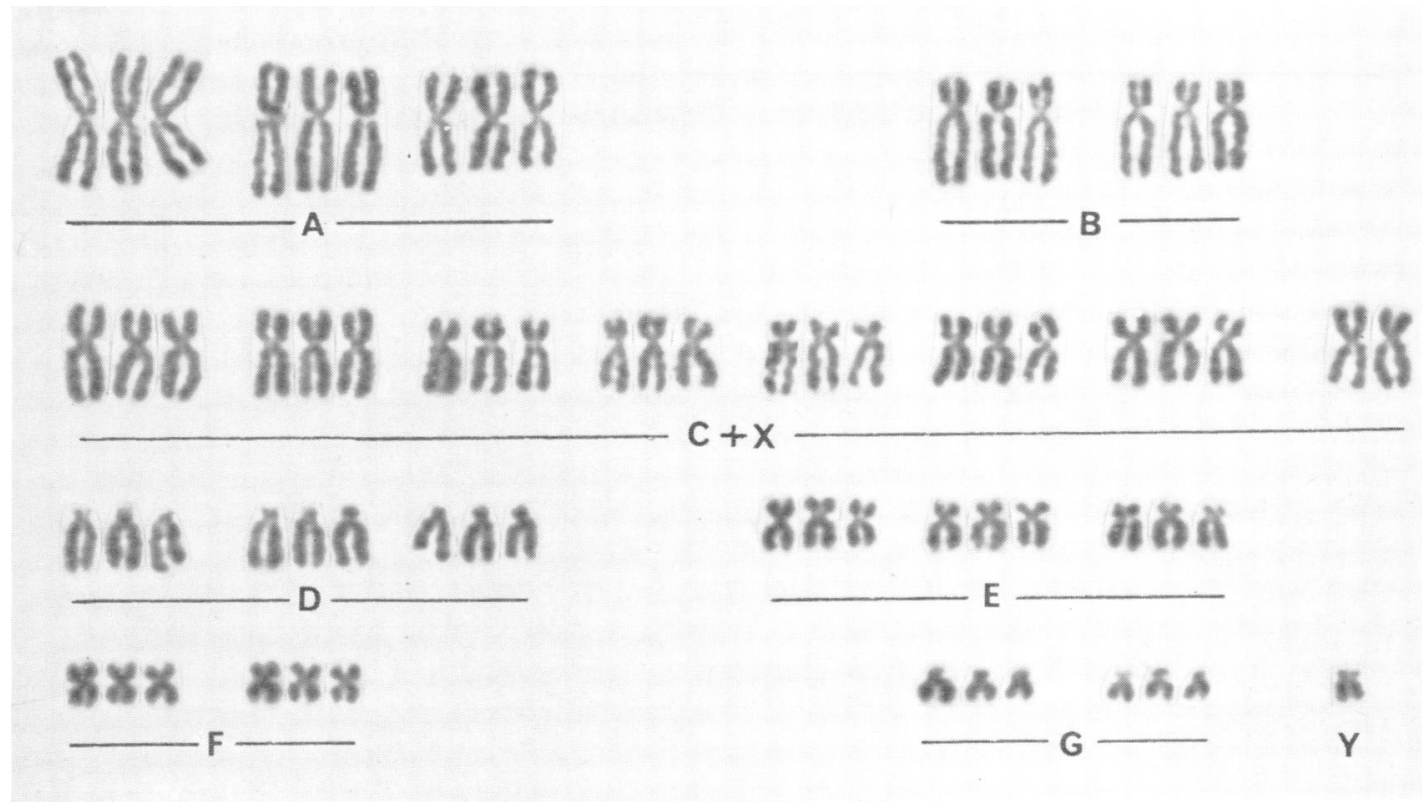

FIG. 3. Karyotype of case 3 showing $2 n=69, X X Y$.

the blood culture without any evidence of mosaicism being found.

\section{Discussion}

The possible modes of origin and aetiology of triploidy in man have been discussed by several authors (Edwards et al, 1967; Schindler and Mikamo, 1970; Carr, 1971). There is evidence (Carr, 1970) that triploidy is increased among abortuses from women who became pregnant within six months of ceasing oral contraception. Of the three cases reported here no information is available on case 1, but oral contraceptives had not been used in case 2 nor in case 3 except some six years previously, and then for only a brief period. The frequency of all triploid conceptuses has been estimated by Carr (1971) to be in the order of $1 \%$, the majority of which apparently abort by the end of the first trimester. The live birth of a triploid infant is however now well documented and Edward et al (1967) have suggested that perhaps, at a maximum, $0.01 \%$ of births would be triploid. This would give a value of approximately 80 per year born throughout England and Wales, yet very few are reported.

This figure may not be an overestimate, however, for our present series of three have been seen in the
Merseyside area over a period of six years. With approximately 140,000 births in the Merseyside area during this time about 14 cases might have been expected. Our three cases were too late for full investigations to be carried out. There were no doubt others which were stillborn and never referred for cytogentic study. It therefore seems worthy of an attempt, from the 13 cases now known of apparently complete triploidy, to look for similarities in the case histories or anatomical features which may prompt obstetricians or paediatricians to refer possible cases for more intensive study.

Common Clinical Features. The pregnancy itself may give rise to clinical concern. The picture may resemble the so called 'maternal syndrome' seen with severe haemolytic disease of the newborn (John and Duncan, 1964). Gross polyhydramnios or hypertension, oedema, and proteinuria may necessitate interruption of pregnancy. Alternatively uterine overdistension may be followed by premature rupture of membranes and spontaneous onset of labour. The enormous placenta commonly results in either primary or secondary post partum haemorrhage, and difficulties with retained placenta.

The high levels of urinary chorionic gonadotrophin reported by Paterson et al (1971) are similarly 
found associated with other conditions in which hyperplacentosis is recognized, such as hydatidiform mole (Beischer et al, 1967; Hobson, 1968), 'maternal syndrome', and diabetes mellitus. It is possible that some cases of otherwise unexplained hydrops foetalis are associated with a triploid karyotype.

A large variety of anomalies are exhibited by the reported cases of triploidy and as yet no clear syndrome can be recognized. There are however more common anomalies which together may indicate possible triploidy. Available data on these more common anomalies are summarized in Table II.

The pure triploid fetus has not been reported as surviving for more than a few hours. The majority are of a low birth weight, though this is not so in case 2 of this report.

The most common malformations of the head are low set, malformed ears, coloboma of the iris, and hypertelorism with occasional palate or lip defects. Skeletal abnormalities of hands and feet include syndactyly, particularly of the third and fourth fingers, flexion deformities, and talipes. Single palmar creases are often present. Internally, polycystic kidney, adrenal hypoplasia, and congenital heart disease, often the cause of death, are frequent. Infants with a $69, \mathrm{XXY}$ chromosome complement invariably have macroscopically abnormal genitalia confirming the imbalance which results from this sex chromosome constitution in a triploid. Hypospadias, a small penis, and non-descent of the testes are common. Less often more extreme degrees of failure of sex differentiation are found as in case 1 of this report.

Perhaps the most consistent abnormality is associated with the placenta. It is often large for the stage of pregnancy and in the majority of cases shows evidence of hydatidiform degeneration. This is particularly significant following the report of Carr (1969) where $70 \%$ of the abortus specimens with hydatidiform degeneration and $13 \%$ with hydatidiform mole were triploid.

We wish to thank Dr E. G. Hall for permission to use the necropsy findings in case 1 .

\section{REFERENCES}

Beischer, N. A., Fortune, D. W., and Fitzgerald, M. G. (1967) Hydatidiform mole and co-existent foetus, both with triploid chromosome constitution. British Medical fournal, 3, 476-478.

Bernard, R. Stahl, A. Coignet, J., Giraud, F., Hartung, M., Brusquet, Y., and Passeron, P. (1967). Triploidie chromosomique chez un nouveau-né polymalformé. Annales de Génétique, 10, 70-74.

Butler, L. J., Chantler, C., France, N. E., and Keith, C. G. (1969) A liveborn infant with complete triploidy $(69, \mathrm{XXX})$. Fournal of Medical Genetics, 6, 413-421. 
II

OF COMPLETE TRIPLOIDY

\begin{tabular}{|c|c|c|c|c|c|c|}
\hline $\begin{array}{l}\text { Keutal et al } \\
(1970)\end{array}$ & $\begin{array}{l}\text { Schindler and } \\
\text { Mikamo (1970) }\end{array}$ & $\underset{(1971)}{\text { Schmickel et al }}$ & $\begin{array}{l}\text { Papiernik- } \\
\text { Berkhauer } \\
\quad(1968)\end{array}$ & Present Case 1 & Present Case 2 & Present Case 3 \\
\hline 22 & 26 & 29 & 24 & 33 & 24 & 32 \\
\hline 36 & 39 & 39 & 41 & 38 & 36 & 36 \\
\hline 1.85 & $1 \cdot 45$ & $2 \cdot 5$ & $1 \cdot 4$ & $2 \cdot 61$ & $3 \cdot 48$ & 1.85 \\
\hline $15 \mathrm{~min}$ & $6 \mathrm{hr}$ & $2 \mathrm{hr}$ & Stillborn & Stillborn & $8 \mathrm{hr}$ & $7 \mathrm{hr}$ \\
\hline$M$ & ? $\mathrm{M}$ & $\mathrm{M}$ & $M$ & $?$ & $\mathbf{F}$ & ? $\mathrm{M}$ \\
\hline $\mathrm{XXY}$ & XXY & $\mathrm{XXY}$ & XXY & $\mathrm{XXY}$ & $\mathrm{xxx}$ & XXY \\
\hline \multirow[t]{2}{*}{-} & + & + & & & & + \\
\hline & + & + & + & - & - & - \\
\hline+ & & & & + & - & + \\
\hline \multirow[t]{4}{*}{+} & + & + & + & & + & + \\
\hline & + & + & & & & + \\
\hline & + & - & + & + & & + \\
\hline & & - & & + & - & \\
\hline+ & & - & & + & - & $?+$ \\
\hline+ & & - & + & + & + & \\
\hline+ & + & & - & - & + & + \\
\hline
\end{tabular}

Carr, D. H. (1969). Cytogenetics and the pathology of hydatidiform degeneration. Obstetrics and Gynecology, 33, 333-341.

Carr, D. H. (1970). Chromosome studies in selected spontaneous abortions: 1. Conception after oral contraceptives. Canadian Medical Association fournal, 103, 343-348.

Carr, D. H. (1971). Chromosome studies in selected spontaneous abortions: Polyploidy in man. Fournal of Medical Genetics, 8, 164-174.

Edwards, J. H., Yuncken, C., Rushton, D. I., Richards, S., and Mittwoch, U. (1967). Three cases of triploidy in man. Cytogenetics, 6, 81-104.

Hobson, B. M. (1968). Pregnancy diagnosis using the Pregnosticon haemagglutination inhibition test. Fournal of Obstetrics and Gynaecology of the British Commonwealth, 75, 718-723.

John, A. H. and Duncan, A. S. (1964). The maternal syndrome associated with hydrops foetalis. Fournal of Obstetrics and Gynaecology of the British Commonwealth, 71, 61-65.

Keutel, J., Dollman, A., and Münster, W. (1970). Triploidie
(69,XXY) bei einem lebend geborenen Kind. Zeitschrift für Kinderheilkunde, 109, 104-117.

Papiernik-Berkhauer, M. E. (1968), Enfant triploide à terme et thérapeutique hormonale. Bulletin de la Fédération des Sociétés de Gynécologie et d'Obstétrique de Langue Française, 20, 248-250.

Paterson, W. G., Hobson, B. M., Smart, G. E., and Bain, A. D.

(1971). 2 cases of hydatidiform degeneration of the placenta with fetal abnormality and triploid chromosome constitution. fournal of Obstetrics and Gynaecology of the British Commonwealth, 78, 136-142.

Schindler, A. M. and Mikamo, K. (1970). Triploidy in man. Cytogenetics, 9, 116-130.

Schmickel, R. D., Silverman, E. M., Floyd, A. D., Payne, F. E., Pooley, J. M., and Beck, M. L. (1971). A live-born infant with 69 chromosomes. Fournal of Pediatrics, 79, 97-103.

Walker, S. (1969). Chromosomes and abortion. In Selected Topics in Medical Genetics. Ed. by C. A. Clarke, pp. 234-239. Oxford University Press, London. 